\title{
Gastrointestinal Peptides as Therapeutic Targets to Mitigate Obesity and Metabolic Syndrome
}

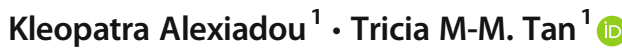

Published online: 21 May 2020

(C) The Author(s) 2020

\begin{abstract}
Purpose of Review Obesity affects over than 600 million adults worldwide resulting in multi-organ complications and major socioeconomic impact. The purpose of this review is to summarise the physiological effects as well as the therapeutic implications of the gut hormones glucagon-like peptide-1 (GLP-1), oxyntomodulin, peptide YY (PYY), and glucose-dependent insulinotropic peptide (GIP) in the treatment of obesity and type 2 diabetes.

Recent Findings Clinical trials have proven that the widely used GLP-1 analogues have pleotropic effects beyond those on weight and glucose metabolism and appear to confer favourable cardiovascular and renal outcomes. However, GLP-1 analogues alone do not deliver sufficient efficacy for the treatment of obesity, being limited by their dose-dependent gastrointestinal side effects. Novel dual agonists for GLP-1/glucagon and GLP-1/GIP are being developed by the pharmaceutical industry and have demonstrated some promising results for weight loss and improvement in glycaemia over and above GLP-1 analogues. Triagonists (for example GLP-1/GIP/glucagon) are currently in pre-clinical or early clinical development.

Summary Gastrointestinal hormones possess complementary effects on appetite, energy expenditure, and glucose metabolism. We highlight the idea that combinations of these hormones may represent the way forward in obesity and diabetes therapeutics.
\end{abstract}

Keywords Obesity · Type 2 diabetes · Gut hormones · GLP-1 · Oxyntomodulin · PYY · GIP

\section{Introduction}

Obesity affects approximately $39 \%$ of the world's adult population which represents a threefold increase since 1975 [1]; more than 1.9 billion adults were overweight in 2016 with emerging data from the USA estimating that by 2030 one in two adults will be obese [2].

Obesity is a multi-systemic disease state with several associated complications such as musculoskeletal issues, obstructive sleep apnoea, cardiovascular disease, infertility, and cancer (endometrial, breast, ovarian, prostate, liver, gallbladder, kidney, and colon) as well as significant metabolic sequelae, the most important being type 2

This article is part of the Topical Collection on Obesity

Tricia M-M. Tan

t.tan@ imperial.ac.uk

1 Department of Digestion, Metabolism and Reproduction, Imperial College London, London, UK diabetes due to its high morbidity and mortality through micro- and macro-vascular complications such as ischaemic heart disease, stroke, and peripheral vascular disease $[3,4]$.

The most effective treatment for obesity and diabetes remission is bariatric surgery with lifestyle intervention and pharmacotherapy being moderately efficacious $[5,6]$. However, bariatric surgery is not available to everyone due to limited availability of specialist surgeons and facilities, patient fitness for surgery, and patient choice [7]. Therefore, there is an unmet need for new and effective treatments for obesity and type 2 diabetes.

Lessons from bariatric surgery have clearly demonstrated that gut hormones are the key players mediating surgery's favourable effects on weight loss and glucose homeostasis, hence making them a promising target for pharmacotherapy $[8,9]$. The current review aims to illustrate the effects of the native peptides on weight and glucose homeostasis and present some data on the currently available and under development gut hormone analogues and will conclude with some future perspectives. 


\section{Glucagon-Like Peptide-1 (GLP-1): Trailblazer for Gut Hormone Therapies}

Glucagon-like peptide 1 (GLP-1) is a 30 amino acid peptide secreted from the enteroendocrine L-cells in response to ingestion of nutrients. It is a product of the post-translational processing of the proglucagon peptide in the L-cells by proconvertase 1 as opposed to the alternative posttranslational processing by proconvertase 2 which releases glucagon in pancreatic $\alpha$ cells (Fig. 1). After release, it is rapidly degraded in plasma by the enzyme dipeptidylpeptidase IV (DPP-IV). GLP-1 is the most extensively studied gut hormone with translational and clinical evidence for its efficacy [10]. Initial studies focused on the role of GLP-1 as an incretin hormone, stimulating glucose-dependent insulin secretion from $\beta$ cells upon nutrient ingestion [11]. Subsequent studies showed the favourable effect of GLP-1 on pancreatic islets as a stimulant for $\beta$ cell proliferation and survival as well as its inhibitory effect on $\alpha$ cells and glucagon secretion, likely through paracrine mechanisms such as inhibitory factors released from $\beta$ cells and through stimulation of local $\delta$ cell somatostatin secretion [12]. Activation of the GLP-1 receptor leads to inhibition of gastric emptying and small bowel motility leading to a slower absorption of nutrients. This action is subject to tachyphylaxis which is detectable within hours [13]. Acute and sustained GLP-1 receptor signalling leads to reduction in appetite and food intake leading to subsequent weight loss $[14,15]$. Emerging data suggest that GLP-1 has pleiotropic effects beyond appetite suppression and weight loss with additional cardioprotective and antiinflammatory roles [16].

GLP-1 analogues have been developed over the last 20 years that incorporate DPP-IV resistance and other modifications that enable convenient daily or even weekly dosing.
The first approved GLP-1 analogue for clinical use was exenatide in 2005, a peptide originally isolated from Heloderma suspectum lizard venom by John Eng in 1992 [17]. Since then, other GLP-1 analogues have been approved including lixisenatide, liraglutide, dulaglutide, albiglutide, and semaglutide. Long-lasting preparations such as exenatide LAR, dulaglutide, and semaglutide enable the effective treatment of type 2 diabetes with one injection a week. In a series of phase 3 trials (LEAD trials), liraglutide was shown to be more effective in reducing $\mathrm{HbA} 1 \mathrm{c}$ by 1.2 to $1.6 \%$ when used either as monotherapy or in combination with other diabetes drugs, whilst conferring weight loss of $2-3 \mathrm{~kg}$, an effect which is especially favourable in comparison to the weight gain associated with insulin glargine or sulphonylurea treatment [18]. The SUSTAIN-1 phase 3 trial demonstrated the safety and tolerability of once-weekly semaglutide injection as monotherapy in patients with type 2 diabetes, achieving reduction in $\mathrm{HbA} 1 \mathrm{c}$ of $1.55 \%$ at the highest dose of semaglutide, $1 \mathrm{mg}$ vs. $0.02 \%$ with placebo. Semaglutide $1 \mathrm{mg}$ weekly was associated with a placebo-subtracted weight loss of $3.5 \mathrm{~kg}$ [19] after 30 weeks. Similar improvements in glycaemia and weight have been obtained with the other GLP-1 analogues and these are now firmly established in treatment pathways for diabetes, especially when priority is being given to weight loss [20]. The next foreseeable development on this frontier will be the introduction of oral semaglutide [21] which promises to extend the benefits of GLP-1 therapy to a greater population of people with diabetes.

Given that GLP-1 analogues were associated with appreciable weight loss effects in people with diabetes, it was natural to examine their effects in people with obesity. The SCALE trial examined the effect of higher doses of liraglutide ( $3 \mathrm{mg}$ once daily vs. placebo) in obesity as a primary indication. At week 56, patients in the liraglutide group had lost a
Fig. 1 Differential posttranslational processing of the proglucagon peptide. GRPP: glicentin-related pancreatic polypeptide; IP-1: intervening peptide-1; GLP-1: glucagon-like peptide-1; IP-2: intervening peptide-2; GLP-2: glucagon-like peptide-2

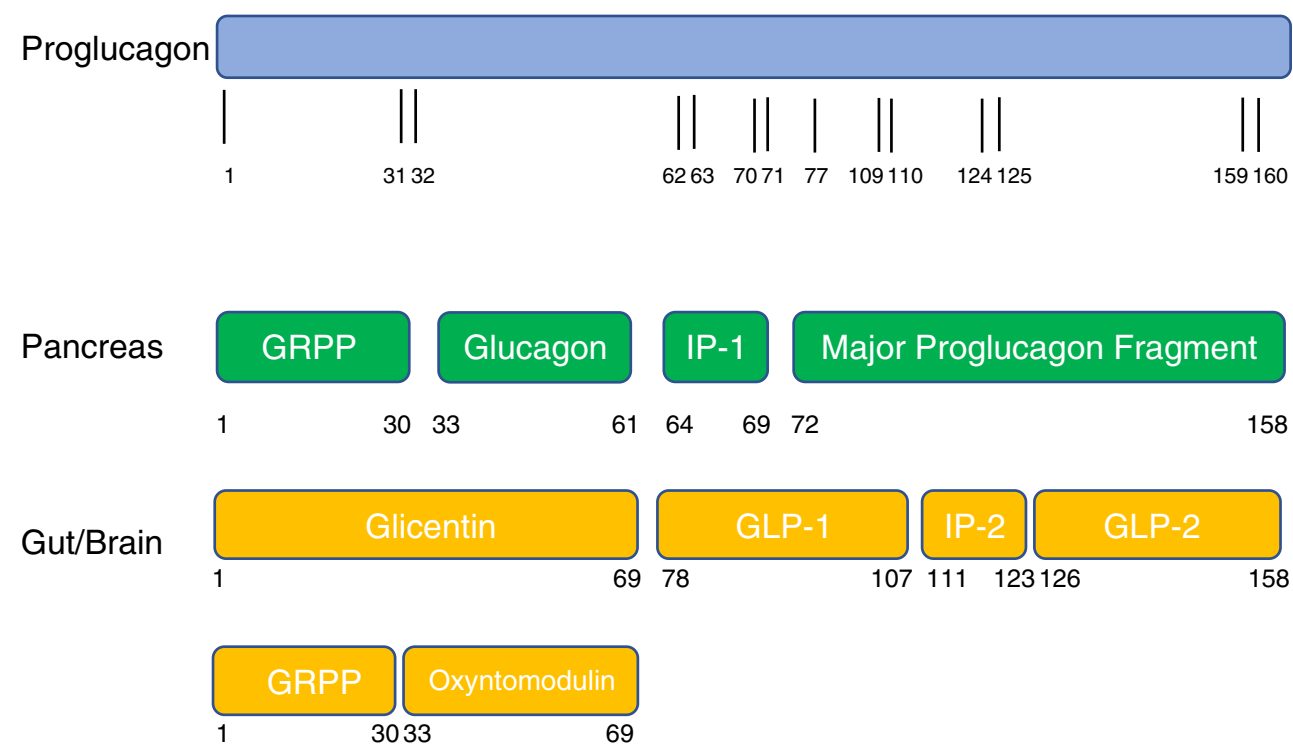


mean of $8.4 \pm 7.3 \mathrm{~kg}$ of body weight, whereas those in the placebo group had lost a mean of $2.8 \pm 6.5 \mathrm{~kg}$ (mean difference of $-5.6 \mathrm{~kg}$ ) [22]. In a phase 2 dose-ranging randomised controlled trial, semaglutide, at doses up to $0.4 \mathrm{mg}$ per day, achieved significantly greater weight loss compared with liraglutide and placebo: $13.8 \%$ at the $0.4 \mathrm{mg}$ /day dose vs. $11.2 \%$ with liraglutide $3 \mathrm{mg}$ per day and $2.3 \%$ for placebo. However, this enhanced efficacy was at the expense of adverse events, mainly nausea, diarrhoea, constipation, and vomiting; $15 \%$ of subjects given the highest dose discontinued the drug due to at least one adverse event as compared with $9 \%$ for liraglutide and 3\% of placebo-treated subjects [23].

GLP-1 has several salutary effects on the cardiovascular system, including anti-inflammatory effects, cardioprotection during ischaemia, natriuresis and diuresis, decreased platelet aggregation, and reduction in post-prandial lipid production [24]. The LEADER trial specifically examined the effect of liraglutide at up to $1.8 \mathrm{mg}$ in people with diabetes at high cardiovascular risk. The liraglutide group had favourable cardiovascular outcomes with a lower risk for the primary composite outcome of the first occurrence of death from cardiovascular causes, nonfatal myocardial infarction, or nonfatal stroke in comparison with placebo [25]. The SUSTAIN-6 trial examined the effect of once-weekly semaglutide $(0.5 \mathrm{or} 1 \mathrm{mg})$ on cardiovascular outcomes in people with type 2 diabetes and again showed a favourable effect on cardiovascular events compared with placebo [26]. Multiple cardiovascular outcome trials (ELIXA-lixisenatide, LEADER-liraglutide, SUSTAIN-6 - semaglutide, EXSCEL - exenatide, Harmony Outcomes-albiglutide, REWIND-dulaglutide, and PIONEER-6 - oral semaglutide) have reported, to a greater or lesser extent, improvements in cardiovascular outcomes, with a systematic review and meta-analysis of these trials involving a combined total of 56,004 participants showing that these drugs as a class reduced major adverse cardiovascular events by $12 \%$, death from cardiovascular causes by $12 \%$, fatal or nonfatal stroke by $16 \%$, and fatal or nonfatal myocardial infarction by $9 \%$. In addition, GLP-1 analogue treatment reduced all-cause mortality by $12 \%$, hospital admission for heart failure by $9 \%$, and a broad composite kidney outcome (development of new-onset macroalbuminuria, decline in estimated glomerular filtration rate [or increase in creatinine], progression to end-stage kidney disease, or death attributable to kidney causes) by $17 \%$, mainly due to a reduction in urinary albumin excretion [27]. As a result, GLP-1 analogues are now recommended for patients with type 2 diabetes who are at high risk of cardiovascular disease [20].

In summary, GLP-1 analogues are mature clinical treatments for diabetes and obesity, with proven efficacy in reducing glycaemia, modestly reducing weight, and reducing cardiovascular events in people with type 2 diabetes at high risk of cardiovascular disease. Oral preparations are in the offing and will expand the appeal of these drugs to prescribers and patients. However, at the highest doses, people treated with GLP-1 analogues experience gastrointestinal side effects, which limits the magnitude of weight loss that can be obtained. Moreover, GLP-1 does not affect energy expenditure in humans [28] which means that this treatment does not compensate for the reduction in energy expenditure that is observed with weight loss, a phenomenon that again limits the weight loss associated with GLP-1 analogue treatment.

\section{Oxyntomodulin and the Concept of Dual GLP-1/Glucagon Agonism}

To take the field of obesity and diabetes therapeutics beyond the proven benefits of GLP-1 analogue therapy, investigators have considered the use of GLP-1 in combination with other gut hormones that may bring complementary benefits. Glucagon is one such candidate: it has long been known that this peptide has insulinotropic effects, reduces food intake, and increases energy expenditure. Moreover, glucagon increases fat oxidation and there is interest in its effects in ameliorating fatty liver disease [29]. However, glucagon has the undesired effect of provoking hyperglycaemia [30].

Proof-of-concept physiological studies have shown that coadministration of GLP-1 and glucagon reduces food intake synergistically and increases energy expenditure. Importantly, GLP-1 ameliorates the hyperglycaemia which is provoked by glucagon $[31,32]$. A natural dual GLP-1/glucagon agonist exists in the shape of oxyntomodulin, a 37 amino acid peptide which is co-secreted with GLP-1 from the L-cells of the small intestine as an additional product of the differential processing of proglucagon in the gut (see Fig. 1) [33]. Oxyntomodulin reduces food intake and increases energy expenditure, leading to significant weight loss in a 28-day clinical study in human volunteers over 28 days [34], and has been shown to improve insulin secretion in short-term clinical studies in people with diabetes [35]. However, the short half-life and rapid renal clearance of native oxyntomodulin hinder its development as a long-term treatment for obesity.

Based on the foregoing data, GLP-1/glucagon receptor agonists are under development. Cotadutide is a balanced GLP1/glucagon dual agonist which has been shown in phase 2 trials in people with diabetes and obesity to significantly improve and to reduce body weight by $2-3 \mathrm{~kg}$ in comparison to placebo [36, 37]. Another GLP-1/glucagon dual agonist, SAR425899, has been shown in phase 1 trials to reduce HbAlc by up to $0.75 \%$ and body weight by up to $5 \mathrm{~kg}$ or so [38]. Further trials are required in order to establish whether these dual GLP-1/glucagon agonists are superior to GLP-1 analogues, and whether the glucagon activity might reverse some of the improvements in glycaemia seen with GLP-1 analogues alone. 


\section{Peptide YY as an Appetite Suppressant}

Peptide YY (PYY) is a 36 amino acid gastrointestinal hormone which is co-secreted from the L-cells together with GLP-1 and oxyntomodulin. The PYY(3-36) peptide is derived from the full-length PYY(1-36) via processing by the enzyme DPP-IV and binds to the neuropeptide Y (NPY) Y2 and Y5 receptors. PYY(3-36) exhibits an anorexic affect through Y2 receptors in the arcuate nucleus and infusion of PYY(3-36) in human volunteers induces a $33 \%$ reduction in food intake over $24 \mathrm{~h}$ [39]. In contrast to GLP-1 and oxyntomodulin, however, PYY(3-36) does not seem to have a marked effect on glucosestimulated insulin secretion when given to human volunteers [40].

Studies using the combination of PYY(3-36) and GLP-1 showed an additive effect in the reduction of food intake in humans [41]. Functional MRI imaging studies show that brain areas implicated in appetite and interest in food are activated when subjects are shown pictures of food. PYY(3-36) and GLP-1 given individually reduce the activation of these areas. The co-infusion of PYY(3-36) and GLP-1 led to a synergistic effect with near-suppression of these areas, correlating with the suppression in appetite as assessed by food intake studies [42]. Co-administration of PYY(3-36) and oxyntomodulin had also an additive effect on the reduction in food intake in humans compared with each peptide alone [43].

PYY(3-36) itself has been studied as a monotherapy for weight loss when delivered nasally in human volunteers, but the efficacy in terms of weight loss was limited by dosedependent adverse events in the form of nausea and vomiting [44], possibly because this preparation and method of delivery led to a rapid release of PYY(3-36) to supraphysiological levels. This contrasts with our experience in infusion studies where the PYY(3-36) levels are increased more slowly and to less marked peaks, leading to better tolerability [39]. PYY analogues continue to be developed to address the narrow therapeutic range of PYY-based drugs with slower release profiles to evade the adverse effects of nausea and vomiting [45] and as weekly injectable treatments such as Novo Nordisk's PYY1875 [46]. Considering these factors, PYY analogues will likely be employed in future in combination with GLP-1 or other gut hormones, to enhance weight loss.

\section{Glucose-Dependent Insulinotropic Peptide (GIP): The 'Twincretin' Combination with GLP-1}

Glucose-dependent insulinotropic polypeptide (GIP) is a 42 amino acid peptide which is synthesised and secreted from neuroendocrine $\mathrm{K}$ cells in the duodenum and jejunum in response to nutrient ingestion. Along with GLP-1, GIP is responsible for the incretin effect, namely the glucose-dependent stimulation of insulin secretion as a response to nutrient ingestion. GIP appears to have a bifunctional 'stabiliser' effect on glucose levels: under hyperglycaemic conditions, it potentiates insulin release whilst not affecting glucagon release, whereas under hypoglycaemic conditions, it increases glucagon release and does not affect insulin secretion [47]. However, GIP possesses other properties which make it unpromising as a therapy for diabetes and obesity. Firstly, under conditions of insulin resistance, such as obesity and type 2 diabetes, GIP promotes lipid deposition in subcutaneous adipocytes [48]. Secondly, GIP does not reduce appetite [49]. Thirdly, GIP's actions on glycaemia seem to be impaired in conditions of chronic hyperglycaemia, which is the principal reason why GIP analogues have not developed for T2D. Indeed, some groups have explored the idea of GIP antagonism to reverse the stimulatory effect of GIP on glucagon secretion and increased fat deposition. The naturally occurring peptide $\operatorname{GIP}(3-30) \mathrm{NH}_{2}$ has been successfully used as an GIP antagonist in human studies, inhibiting the incretin effect of GIP as well as its effect on glucagon secretion [50,51], but the therapeutic potential of GIP antagonism is still not clear.

Interestingly, normalisation of glucose levels using insulin restores the incretin properties of GIP in diabetes [52]. The above data suggest that there is scope for a GLP-1 and GIP dual agonist combination (the so-called twincretin concept), where the former would restore euglycemia, permitting the latter to exert its full insulinotropic potential, thus synergistically improving glucose levels. Short-term infusion studies utilising the GLP-1/GIP combination compared with single GLP-1 infusion have failed to show an advantage of the combination over GLP-1 alone [49, 53, 54]. Nevertheless, pharmaceutical companies have pursued the 'twincretin' concept, developing GLP-1/GIP dual agonists such as tirzepatide, an analogue biased in favour of GIP over GLP-1 activity [55], and NNC0090-2746, another analogue with balanced GLP-1 and GIP activity [56]. Intriguingly, a phase 2B clinical trial of tirzepatide in people with diabetes and obesity suggested that this analogue, at the highest doses tested, has superior effects on glycaemia in comparison to the benchmark GLP-1 analogue dulaglutide (reductions in $\mathrm{HbA} 1 \mathrm{c}$ of $1.9 \%$ vs. $1.2 \%$ when given for 26 weeks) as well as weight loss (reductions of $11.3 \mathrm{~kg}$ vs. $2.7 \mathrm{~kg}$ ) albeit with a worse gastrointestinal side effect profile [57]. The phase 2a trials of NNC0090-2746 in people with diabetes and obesity also showed significant improvements in $\mathrm{HbA} 1 \mathrm{c}$ over placebo with a placebo-subtracted reduction of $0.96 \%$ over 12 weeks' treatment, as well as placebosubtracted reductions in weight of up to $1.8 \%$ [56]. GLP$1 /$ GIP twincretins therefore show some promise at this stage. 


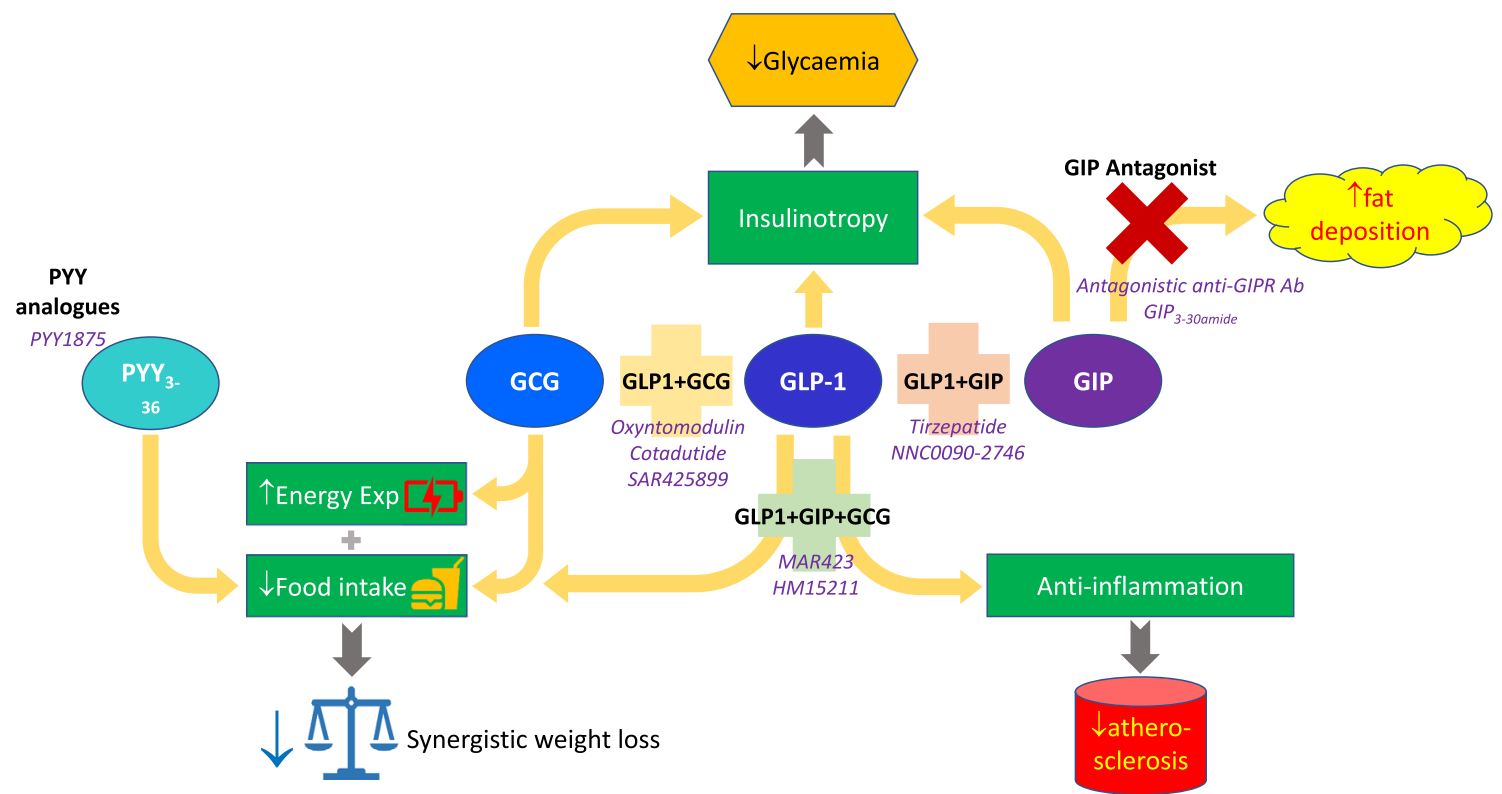

Fig. 2 Complementary actions of gut hormone receptors combine to achieve desirable therapeutic outcomes. GCG: glucagon; GIP: glucose-dependent insulinotropic polypeptide; GLP-1: glucagon-like peptide-1; PYY: peptide YY

\section{Triagonism: Is Three Better than Two?}

It is theoretically possible that, by blending three complementary gut hormone actions, we may be able to obtain enhanced efficacies over dual agonism. The physiological changes from bariatric surgery may serve as a model for this concept. Surgery, and in particular Roux-en-Y gastric bypass (RYGB), exerts many of its beneficial effects by activating the exaggerated release of GLP-1, oxyntomodulin, and peptide YY after eating, leading to improvements in glucose metabolism, suppression of appetite, and reductions in body weight $[8,9]$. Building on this observation, we used a subcutaneous infusion pump to deliver a combination of GLP1/oxyntomodulin/PYY(3-36) (GOP) at doses to replicate the elevated post-prandial levels found after bariatric surgery [58]. When administered for up to $12 \mathrm{~h}$ per day for 28 days in obese people with pre-diabetes/type 2 diabetes, we showed that GOP infusion achieves superior glucose tolerance and reduced glucose variability compared with RYGB and has a favourable effect on body weight. Our proof-of-concept study suggests that triple agonism of the GLP-1, glucagon, and Y2 receptors using the GOP combination may possess advantages even over RYGB, hitherto considered the standard-of-care for treatment of obesity and diabetes, and further studies are planned to explore the doses and combinations to obtain optimal efficacies [59].

Other groups have explored the concept of GLP-1/GIP/ glucagon triagonism to obtain extra benefits from adding the benefits of glucagon action (promotion of energy expenditure and amelioration of fatty liver disease) to the 'twincretin' effects of GLP-1 and GIP. These properties were combined in the design of the unimolecular triagonist MAR423 with promising results in animal models which have been taken forward to an ongoing phase 1 trial [60]. HM15211 is another triagonist compound which has shown favourable preclinical data in animal models of steatohepatitis [61-63] and which is currently in phase 1 trials.

\section{Conclusions}

GLP-1 and its analogues have been the trailblazers for the concept of gut hormone therapy of diabetes and obesity. However, the dimensions of the global obesity and diabetes pandemics call for the development of new, effective, practical, and scalable treatments which will overcome the limitations of the GLP-1 analogues. Dual and triple hormone combinations are emerging as a promising strategy for such development (Fig. 2), but it seems fair to say that academic researchers and pharmaceutical industry have not yet struck on the optimal combination for treatment at this present moment. Moreover, even if the current dual and triple agonists successfully make it to market, it remains unknown whether they will inherit the same cardiovascular and renal benefits that have been identified for GLP-1. We await the data that will help us to identify such optimal combinations to achieve the promise of enhanced efficacy for weight loss and improvements in glycaemia without undue side effects.

Funding Information This article presents independent research funded by the NIHR and supported by the NIHR CRF and BRC at Imperial College Healthcare NHS Trust. The Department of Digestion, Metabolism and Reproduction is funded by grants from the MRC, BBSRC, NIHR, an Integrative Mammalian Biology (IMB) Capacity Building Award, an FP7- HEALTH-2009-241592 EuroCHIP grant and is supported by the NIHR Biomedical Research Centre Funding Scheme. 


\section{Compliance with Ethical Standards}

Disclaimer The views expressed are those of the author(s) and not necessarily those of the NHS, the NIHR, or the Department of Health.

Open Access This article is licensed under a Creative Commons Attribution 4.0 International License, which permits use, sharing, adaptation, distribution and reproduction in any medium or format, as long as you give appropriate credit to the original author(s) and the source, provide a link to the Creative Commons licence, and indicate if changes were made. The images or other third party material in this article are included in the article's Creative Commons licence, unless indicated otherwise in a credit line to the material. If material is not included in the article's Creative Commons licence and your intended use is not permitted by statutory regulation or exceeds the permitted use, you will need to obtain permission directly from the copyright holder. To view a copy of this licence, visit http://creativecommons.org/licenses/by/4.0/.

\section{References}

1. World Health Organisation. Obesity and Overweight: Fact Sheet 2020 [updated 2020-03-03]. Available from: https://www.who.int/ news-room/fact-sheets/detail/obesity-and-overweight. Accessed 03 Mar 2020

2. Ward ZJ, Bleich SN, Cradock AL, Barrett JL, Giles CM, Flax C, et al. Projected U.S. state-level prevalence of adult obesity and severe obesity. N Engl J Med. 2019;381(25):2440-50.

3. De Lorenzo A, Romano L, Di Renzo L, Di Lorenzo N, Cenname G, Gualtieri P. Obesity: a preventable, treatable, but relapsing disease. Nutrition. 2020;71:110615.

4. Barnett R. Type 2 diabetes. Lancet. 2019;394(10198):557.

5. Sudlow A, le Roux CW, Pournaras DJ. Review of multimodal treatment for type 2 diabetes: combining metabolic surgery and pharmacotherapy. Ther Adv Endocrinol Metab. 2019;10: 2042018819875407

6. Avenell A, Robertson C, Skea Z, Jacobsen E, Boyers D, Cooper D, et al. Bariatric surgery, lifestyle interventions and orlistat for severe obesity: the REBALANCE mixed-methods systematic review and economic evaluation. Health Technol Assess. 2018;22(68):1-246.

7. Gulliford MC, Charlton J, Prevost T, Booth H, Fildes A, Ashworth $\mathrm{M}$, et al. Costs and outcomes of increasing access to bariatric surgery: cohort study and cost-effectiveness analysis using electronic health records. Value Health. 2017;20(1):85-92.

8. le Roux CW, Welbourn R, Werling M, Osborne A, Kokkinos A, Laurenius A, et al. Gut hormones as mediators of appetite and weight loss after Roux-en-Y gastric bypass. Ann Surg. 2007;246(5):780-5

9. Abdeen G, le Roux CW. Mechanism underlying the weight loss and complications of Roux-en-Y gastric bypass. Review. Obes Surg. 2016;26(2):410-21.

10. Holst JJ. The physiology of glucagon-like peptide 1. Physiol Rev. 2007;87(4):1409-39.

11. Drucker DJ, Nauck MA. The incretin system: glucagon-like peptide-1 receptor agonists and dipeptidyl peptidase-4 inhibitors in type 2 diabetes. Lancet. 2006;368(9548):1696-705.

12. Campbell JE, Drucker DJ. Pharmacology, physiology, and mechanisms of incretin hormone action. Cell Metab. 2013;17(6):819-37.

13. Nauck MA, Kemmeries G, Holst JJ, Meier JJ. Rapid tachyphylaxis of the glucagon-like peptide 1-induced deceleration of gastric emptying in humans. Diabetes. 2011;60(5):1561-5.
14. Naslund E, King N, Mansten S, Adner N, Holst JJ, Gutniak M, et al. Prandial subcutaneous injections of glucagon-like peptide-1 cause weight loss in obese human subjects. Br J Nutr. 2004;91(3):439-46.

15. Bagger JI, Holst JJ, Hartmann B, Andersen B, Knop FK, Vilsboll T. Effect of oxyntomodulin, glucagon, GLP-1, and combined glucagon +GLP-1 infusion on food intake, appetite, and resting energy expenditure. J Clin Endocrinol Metab. 2015;100(12):4541-52.

16. Marx N, Libby P. Cardiovascular benefits of GLP-1 receptor agonism: is inflammation a key? JACC Basic Transl Sci. 2018;3(6):858-60.

17. Eng J, Kleinman WA, Singh L, Singh G, Raufman JP. Isolation and characterization of exendin-4, an exendin-3 analogue, from Heloderma suspectum venom. Further evidence for an exendin receptor on dispersed acini from guinea pig pancreas. J Biol Chem. 1992;267(11):7402-5.

18. Blonde L, Russell-Jones D. The safety and efficacy of liraglutide with or without oral antidiabetic drug therapy in type 2 diabetes: an overview of the LEAD 1-5 studies. Diabetes Obes Metab. 2009;11(Suppl 3):26-34.

19. Sorli C, Harashima SI, Tsoukas GM, Unger J, Karsbol JD, Hansen $\mathrm{T}$, et al. Efficacy and safety of once-weekly semaglutide monotherapy versus placebo in patients with type 2 diabetes (SUSTAIN 1): a double-blind, randomised, placebo-controlled, parallel-group, multinational, multicentre phase 3a trial. Lancet Diabetes Endocrinol. 2017;5(4):251-60.

20. Buse JB, Wexler DJ, Tsapas A, Rossing P, Mingrone G, Mathieu C, et al. 2019 update to: management of hyperglycaemia in type 2 diabetes, 2018. A consensus report by the American Diabetes Association (ADA) and the European Association for the Study of Diabetes (EASD). Diabetologia. 2020;63(2):221-8.

21. Pratley R, Amod A, Hoff ST, Kadowaki T, Lingvay I, Nauck M, et al. Oral semaglutide versus subcutaneous liraglutide and placebo in type 2 diabetes (PIONEER 4): a randomised, double-blind, phase 3a trial. Lancet. 2019;394(10192):39-50.

22. Pi-Sunyer X, Astrup A, Fujioka K, Greenway F, Halpern A, Krempf $\mathrm{M}$, et al. A randomized, controlled trial of $3.0 \mathrm{mg}$ of liraglutide in weight management. N Engl J Med. 2015;373(1):11-22.

23. O'Neil PM, Birkenfeld AL, McGowan B, Mosenzon O, Pedersen SD, Wharton S, et al. Efficacy and safety of semaglutide compared with liraglutide and placebo for weight loss in patients with obesity: a randomised, double-blind, placebo and active controlled, doseranging, phase 2 trial. Lancet. 2018;392(10148):637-49.

24. Drucker DJ. The cardiovascular biology of glucagon-like peptide-1. Cell Metab. 2016;24(1):15-30.

25. Marso SP, Daniels GH, Brown-Frandsen K, Kristensen P, Mann JF, Nauck MA, et al. Liraglutide and cardiovascular outcomes in type 2 diabetes. N Engl J Med. 2016;375(4):311-22.

26. Marso SP, Bain SC, Consoli A, Eliaschewitz FG, Jodar E, Leiter LA, et al. Semaglutide and cardiovascular outcomes in patients with type 2 diabetes. N Engl J Med. 2016;375(19):1834-44.

27. Kristensen SL, Rorth R, Jhund PS, Docherty KF, Sattar N, Preiss D, et al. Cardiovascular, mortality, and kidney outcomes with GLP-1 receptor agonists in patients with type 2 diabetes: a systematic review and meta-analysis of cardiovascular outcome trials. Lancet Diabetes Endocrinol. 2019;7(10):776-85.

28. Flint A, Raben A, Rehfeld JF, Holst JJ, Astrup A. The effect of glucagon-like peptide-1 on energy expenditure and substrate metabolism in humans. Int J Obes Relat Metab Disord. 2000;24(3):288-98.

29. Finan B, Capozzi ME, Campbell JE. Repositioning glucagon action in the physiology and pharmacology of diabetes. Diabetes. 2020;69(4):532-41.

30. Scott RV, Bloom SR. Problem or solution: the strange story of glucagon. Peptides. 2018;100:36-41.

31. Cegla J, Troke RC, Jones B, Tharakan G, Kenkre J, McCullough KA, et al. Coinfusion of low-dose GLP-1 and glucagon in man results in a reduction in food intake. Diabetes. 2014;63(11):3711-20. 
32. Tan TM, Field BC, McCullough KA, Troke RC, Chambers ES, Salem V, et al. Coadministration of glucagon-like peptide-1 during glucagon infusion in humans results in increased energy expenditure and amelioration of hyperglycemia. Diabetes. 2013;62(4):1131-8.

33. Holst JJ, Albrechtsen NJW, Gabe MBN, Rosenkilde MM. Oxyntomodulin: actions and role in diabetes. Peptides. 2018;100:48-53.

34. Wynne K, Park AJ, Small CJ, Meeran K, Ghatei MA, Frost GS, et al. Oxyntomodulin increases energy expenditure in addition to decreasing energy intake in overweight and obese humans: a randomised controlled trial. Int J Obes. 2006;30(12):1729-36.

35. Shankar SS, Shankar RR, Mixson LA, Miller DL, Pramanik B, O'Dowd AK, et al. Native oxyntomodulin has significant glucoregulatory effects independent of weight loss in obese humans with and without type 2 diabetes. Diabetes. 2018;67(6):1105-12.

36. Ambery P, Parker VE, Stumvoll M, Posch MG, Heise T, PlumMoerschel L, et al. MEDI0382, a GLP-1 and glucagon receptor dual agonist, in obese or overweight patients with type 2 diabetes: a randomised, controlled, double-blind, ascending dose and phase 2a study. Lancet. 2018;391(10140):2607-18.

37. Parker VER, Robertson D, Wang T, Hornigold DC, Petrone M, Cooper AT, et al. Efficacy, safety, and mechanistic insights of cotadutide, a dual receptor glucagon-like peptide-1 and glucagon agonist. J Clin Endocrinol Metab. 2020;105(3):dgz047.

38. Tillner J, Posch MG, Wagner F, Teichert L, Hijazi Y, Einig C, et al. A novel dual glucagon-like peptide and glucagon receptor agonist SAR425899: results of randomized, placebo-controlled first-in-human and first-in-patient trials. Diabetes Obes Metab. 2019;21(1):120-8.

39. Batterham RL, Cowley MA, Small CJ, Herzog H, Cohen MA, Dakin CL, et al. Gut hormone PYY(3-36) physiologically inhibits food intake. Nature. 2002;418(6898):650-4.

40. Tan TM, Salem V, Troke RC, Alsafi A, Field BC, De Silva A, et al. Combination of peptide YY3-36 with GLP-1(7-36) amide causes an increase in first-phase insulin secretion after IV glucose. J Clin Endocrinol Metab. 2014;99(11):E2317-24

41. Neary NM, Small CJ, Druce MR, Park AJ, Ellis SM, Semjonous NM, et al. Peptide YY3-36 and glucagon-like peptide-17-36 inhibit food intake additively. Endocrinology. 2005;146(12):5120-7.

42. De Silva A, Salem V, Long CJ, Makwana A, Newbould RD, Rabiner EA, et al. The gut hormones PYY 3-36 and GLP-1 7-36 amide reduce food intake and modulate brain activity in appetite centers in humans. Cell Metab. 2011;14(5):700-6.

43. Field BC, Wren AM, Peters V, Baynes KC, Martin NM, Patterson M, et al. PYY3-36 and oxyntomodulin can be additive in their effect on food intake in overweight and obese humans. Diabetes. 2010;59(7):1635-9.

44. Gantz I, Erondu N, Mallick M, Musser B, Krishna R, Tanaka WK, et al. Efficacy and safety of intranasal peptide YY3-36 for weight reduction in obese adults. J Clin Endocrinol Metab. 2007;92(5):1754-7.

45. Rangwala SM, D'Aquino K, Zhang YM, Bader L, Edwards W, Zheng S, et al. A Long-acting PYY3-36 analog mediates robust anorectic efficacy with minimal emesis in nonhuman primates. Cell Metab. 2019;29(4):837-43 e5.

46. Novo Nordisk. Annual Report 2019 Available from: https:// annualreport2019.novonordisk.com/section/pipeline overview. Accessed 03 Mar 2020

47. Christensen M, Vedtofte L, Holst JJ, Vilsboll T, Knop FK. Glucose-dependent insulinotropic polypeptide: a bifunctional glucose-dependent regulator of glucagon and insulin secretion in humans. Diabetes. 2011;60(12):3103-9.

48. Thondam SK, Daousi C, Wilding JP, Holst JJ, Ameen GI, Yang C, et al. Glucose-dependent insulinotropic polypeptide promotes lipid deposition in subcutaneous adipocytes in obese type 2 diabetes patients: a maladaptive response. Am J Physiol Endocrinol Metab. 2017;312(3):E224-E33.

49. Bergmann NC, Lund A, Gasbjerg LS, Meessen ECE, Andersen MM, Bergmann S, et al. Effects of combined GIP and GLP-1 infusion on energy intake, appetite and energy expenditure in overweight/obese individuals: a randomised, crossover study. Diabetologia. 2019;62(4):665-75.

50. Gasbjerg LS, Christensen MB, Hartmann B, Lanng AR, SparreUlrich AH, Gabe MBN, et al. GIP(3-30)NH2 is an efficacious GIP receptor antagonist in humans: a randomised, double-blinded, placebo-controlled, crossover study. Diabetologia. 2018;61(2):413-23.

51. Gasbjerg LS, Helsted MM, Hartmann B, Sparre-Ulrich AH, Veedfald S, Stensen S, et al. GIP and GLP-1 receptor antagonism during a meal in healthy individuals. J Clin Endocrinol Metab. 2020;105(3): dgz175.

52. Hojberg PV, Vilsboll T, Rabol R, Knop FK, Bache M, Krarup T, et al. Four weeks of near-normalisation of blood glucose improves the insulin response to glucagon-like peptide-1 and glucosedependent insulinotropic polypeptide in patients with type 2 diabetes. Diabetologia. 2009;52(2):199-207.

53. Gasbjerg LS, Helsted MM, Hartmann B, Jensen MH, Gabe MBN, Sparre-Ulrich AH, et al. Separate and combined glucometabolic effects of endogenous glucose-dependent insulinotropic polypeptide and glucagon-like peptide 1 in healthy individuals. Diabetes. 2019;68(5):906-17.

54. Daousi C, Wilding JP, Aditya S, Durham BH, Cleator J, Pinkney $\mathrm{JH}$, et al. Effects of peripheral administration of synthetic human glucose-dependent insulinotropic peptide (GIP) on energy expenditure and subjective appetite sensations in healthy normal weight subjects and obese patients with type 2 diabetes. Clin Endocrinol. 2009;71(2):195-201.

55. Coskun T, Sloop KW, Loghin C, Alsina-Fernandez J, Urva S, Bokvist KB, et al. LY3298176, a novel dual GIP and GLP-1 receptor agonist for the treatment of type 2 diabetes mellitus: from discovery to clinical proof of concept. Mol Metab. 2018;18:3-14.

56. Frias JP, Bastyr EJ 3rd, Vignati L, Tschop MH, Schmitt C, Owen $\mathrm{K}$, et al. The sustained effects of a dual GIP/GLP-1 receptor agonist, NNC0090-2746, in patients with type 2 diabetes. Cell Metab. 2017;26(2):343-52 e2.

57. Frias JP, Nauck MA, Van J, Kutner ME, Cui X, Benson C, et al. Efficacy and safety of LY3298176, a novel dual GIP and GLP-1 receptor agonist, in patients with type 2 diabetes: a randomised, placebo-controlled and active comparator-controlled phase 2 trial. Lancet. 2018;392(10160):2180-93.

58. Tan T, Behary P, Tharakan G, Minnion J, Al-Najim W, Albrechtsen NJW, et al. The effect of a subcutaneous infusion of GLP-1, OXM, and PYY on energy intake and expenditure in obese volunteers. J Clin Endocrinol Metab. 2017;102(7):2364-72.

59. Behary P, Tharakan G, Alexiadou K, Johnson N, Wewer Albrechtsen NJ, Kenkre J, et al. Combined GLP-1, oxyntomodulin, and peptide YY improves body weight and glycemia in obesity and prediabetes/type 2 diabetes: a randomized, single-blinded, placebocontrolled study. Diabetes Care. 2019;42(8):1446-53.

60. Brandt SJ, Gotz A, Tschop MH, Muller TD. Gut hormone polyagonists for the treatment of type 2 diabetes. Peptides. 2018;100:190-201.

61. Finan B, Yang B, Ottaway N, Smiley DL, Ma T, Clemmensen C, et al. A rationally designed monomeric peptide triagonist corrects obesity and diabetes in rodents. Nat Med. 2015;21(1):27-36.

62. Tschop MH, Finan B, Clemmensen C, Gelfanov V, Perez-Tilve D, Muller TD, et al. Unimolecular polypharmacy for treatment of diabetes and obesity. Cell Metab. 2016;24(1):51-62.

63. Jall S, Sachs S, Clemmensen C, Finan B, Neff F, DiMarchi RD, et al. Monomeric GLP-1/GIP/glucagon triagonism corrects obesity, hepatosteatosis, and dyslipidemia in female mice. Mol Metab. 2017;6(5):440-6.

Publisher's Note Springer Nature remains neutral with regard to jurisdictional claims in published maps and institutional affiliations. 